\title{
A polymorphism for a lethal phenotype governed by two duplicate genes in Mimulus guttatus
}

\author{
MARK R. MACNAIR \\ Department of Biological Sciences, Hatherly Laboratories, University of Exeter, Prince of Wales Road, Exeter EX4 4PS,
}

U.K.

\begin{abstract}
A polymorphism in a British population of Mimulus guttatus for an albino phenotype controlled by two duplicate genes is described. This polymorphism is shown to be allelic with one studied previously by Kiang \& Libby (1972) in California. The polymorphism has remained stable between 1977 and 1991. Some substructuring of the population is evident, with the double heterozygote being the most frequent phenotype in the main stream flowing through the study site. The theoretical problems associated with the maintenance of a two locus polymorphism are discussed.
\end{abstract}

Keywords: albino mutation, multilocus polymorphism, selection.

\section{Introduction}

Many characters are governed by single genes, and phenotypic variation can be produced by a polymorphism at such loci. The conditions for stable polymorphism of such systems are reasonably well known, although there is still considerable controversy as to how frequent the various possible mechanisms are in nature, and as to the size of the selective coefficients (Endler, 1986). However, many other characters are produced by the epistatic interaction of two or more loci: there are fewer examples of polymorphism of such systems, and the conditions for polymorphism are much less clear (Karlin, 1975; Renaud \& Morton, 1991). There is even less consensus as to the types of selection acting on such systems in nature, although some well studied systems are undoubtedly acted on by selection (e.g. banding in snails, Jones et al., 1977; cyanogenesis in clover, Hughes, 1991).

Many polymorphisms for chlorophyll-deficient mutants are known in wild and cultivated plants (see Crumpacker, 1967 for a review). Kiang \& Libby (1972) described a polymorphism for an albino phenotype in a population of Mimulus guttatus from Northern California which had persisted for many years. They ascribed this variation to a single gene, and found evidence that the albino gene showed a high mutation rate, some degree of segregation distortion, and heterozygotes showed a greater potential for vegetative reproduction. They suggested that the poly- morphism was maintained by linkage disequilibrium with another, unidentified, locus.

This paper describes a polymorphism for an albino phenotype in $M$. guttatus, which is produced by two duplicate genes. The allelism of this system with that studied by Kiang \& Libby (1972) is investigated.

\section{Materials and methods}

\section{Provenance of the plants}

M. guttatus is a hydrophilic species, native of western North America, that has been naturalized in the U.K. for at least 160 years (Roberts, 1964). The plants are readily emasculated and are self-compatible. Seeds are ripe in about 2-3 weeks. The population studied in this paper is located at Cerrigydrudion, N. Wales (map ref. SH956474). The plant is locally common, inhabiting the main stream (Afon Ceirw) and a number of manmade ditches draining into it (Fig. 1). Plants were sampled in two ways:

As cuttings. Individuals were sampled in spring (March or April), with cuttings being collected at random. Plants were then potted up in the greenhouse, grown to flowering, and selfed.

As seeds. Individuals were sampled in summer (July or August), with two or three capsules collected from individual stems at random. 


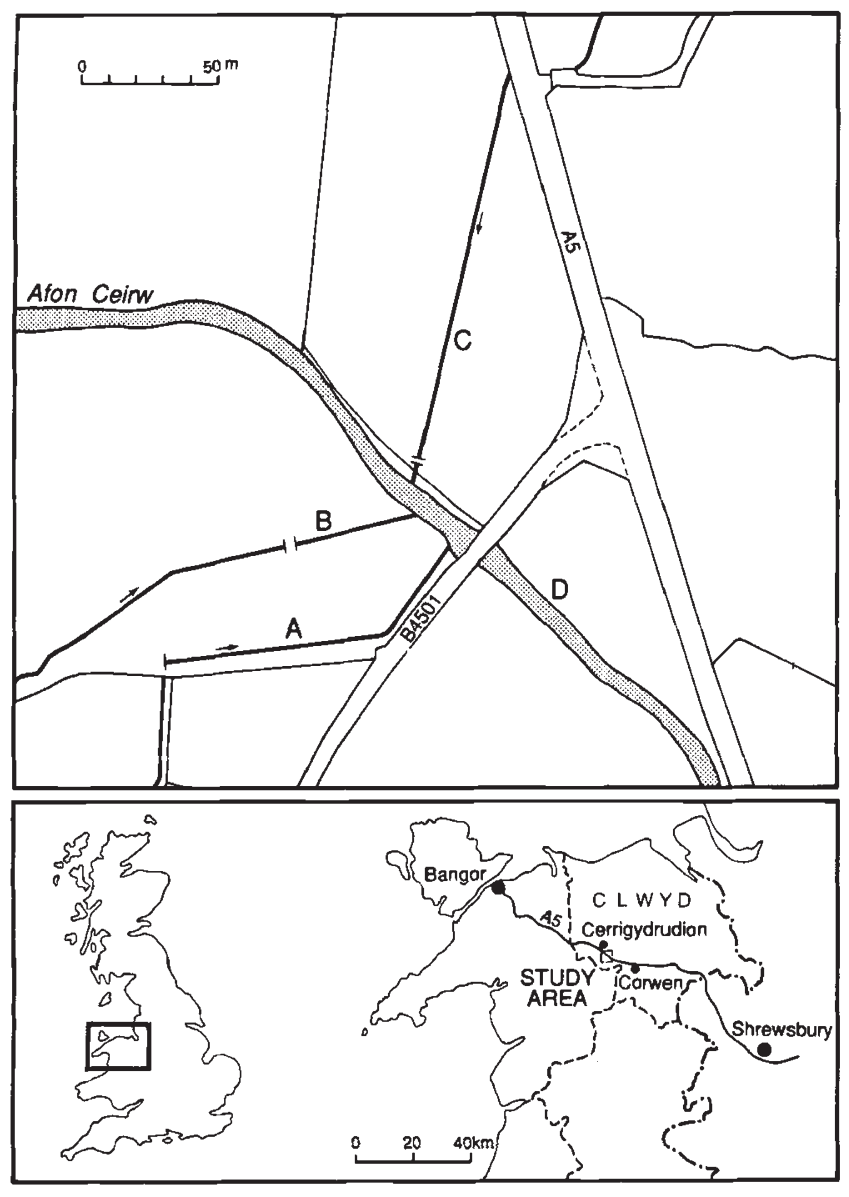

Fig. 1 Lower: map of Britain showing location of study site; upper: detailed map of the study site showing location of the streams (A, B, C and D) referred to in the text.

In 1977, a bulk seed sample was obtained from the population studied by Kiang \& Libby (1972) at Schneider Creek, California.

\section{Scoring for albinism}

Seeds were sown onto damp filter paper in plastic petri dishes. Dishes were scored daily and all germinating seedlings scored destructively. Seedlings were scored as green, albino or speckled. Speckled seedlings had both green and albino sectors. The proportion of green in speckled seedlings varied considerably. When germination had apparently finished, dishes were allowed to dry out. Ungerminated seeds were separated from empty seed cases. Where these were a significant proportion of the germinated fraction, they were transferred to fresh filter paper and rewetted to allow further germination. In most crosses reported in this paper, final germination was over 90 per cent.

\section{Results}

\section{Genetics of the albino phenotype}

The results of a number of selfs from plants collected in the wild are given in Table 1. If the albino and speckled phenotypes were thought to be different, the proportions produced are very difficult to interpret. However, if albino and speckled seedlings are considered as one class with the same basic genotype, families clearly fall into three categories: some produce no albino progeny $(1: 0)$, others segregate in a $3: 1$ ratio, while others segregate in a 15:1 ratio. These results suggest that this phenotype is the product of two unlinked genes showing duplicate epistasis. The albino phenotype is aabb, the $15: 1$ phenotype has genotype $A a B b$, while the 3:1 phenotype is produced by $A a b b$ or $a a B b$. All other genotypes produce 1:0 ratios. This interpretation was confirmed by the results of crosses between these plants (Table 2). Crosses of $A a B b$ with either $A a b b$ or $a a B b$ should produce 7:1 ratios, while all crosses between 3:1 plants should produce 3:1 ratios in their turn. It was sometimes possible to obtain adult plants in the greenhouse from speckled seedlings with a considerable proportion of green: one of these (M16) was also included in these crosses. Crosses between such plants $(a a b b)$ and $A a B b$ should segregate in a 3:1 ratio, while crosses to either 3:1 genotype should segregate $1: 1$. It is clear that the majority of crosses segregate in the ratios predicted on the two locus model.

There are some crosses which produce ratios with fewer than predicted albinos. For the sake of brevity not all selfs were included in Table 1: it includes all the plants that were later used for crosses (Table 2) plus some other representative plants. As plants with odd segregations were used preferentially in crosses to test the hypothesis, there is some over-representation of abnormal segregations in these tables. However, apart from type 1 errors, two causes of reduced albino proportion can be identified, both of which have been found in other analyses of albino mutations (Kirk \& Tilney-Bassett, 1978). First, it is clear that albino seedlings germinate more slowly and have a lower probability of germinating on the first occasion than green seedlings. There were 29 crosses that had produced sufficient seedlings (between 30 and 498) after being dried out and transferred to fresh filter paper for a meaningful comparison to be made between the proportions of albinos produced in the two germinations. The proportions were compared with $2 \times 2$ chisquared analysis. Of the 29 comparisons, 28 had a higher proportion of albinos on the second occasion, and of these 28,12 were significant at the 5 per cent level. Everitt (1977) gives a method for combining the 
Table 1 Results of selfing a number of plants from Cerrigydrudion. Most plants were collected from the wild in 1976, and the prefix indicates their provenance (see Fig. 1). Others were grown from seed (prefix Cer)

\begin{tabular}{|c|c|c|c|c|c|c|}
\hline \multirow[b]{2}{*}{ Plant } & \multicolumn{3}{|c|}{ Number of scedlings } & \multirow{2}{*}{$\begin{array}{l}\text { Total } \\
\text { white }\end{array}$} & \multirow[b]{2}{*}{ Ratio } & \multirow[b]{2}{*}{$\chi^{2}$} \\
\hline & Green & Albino & Speckled & & & \\
\hline Al & 541 & 164 & 1 & 165 & $3: 1$ & $1.00 \mathrm{~ns}$ \\
\hline B2 & 484 & 66 & 40 & 106 & $3: 1$ & $15.56^{* * *}$ \\
\hline B4 & 329 & 49 & 40 & 89 & $3: 1$ & $3.07 \mathrm{~ns}$ \\
\hline B6 & 955 & 46 & 27 & 73 & $15: 1$ & $1.27 \mathrm{~ns}$ \\
\hline B9 & 1115 & 34 & 52 & 86 & $15: 1$ & $1.70 \mathrm{~ns}$ \\
\hline B10 & 727 & 34 & 17 & 51 & $15: 1$ & $0.12 \mathrm{~ns}$ \\
\hline $\mathrm{C} 2$ & 223 & 48 & 0 & 48 & $3: 1$ & $7.67 * *$ \\
\hline $\mathrm{C} 3$ & 46.3 & 0 & 0) & 0 & $1: 0$ & - \\
\hline C6 & 5.38 & 112 & 41 & 153 & $3: 1$ & $3.01 \mathrm{~ns}$ \\
\hline $\mathrm{C} 7$ & 588 & 12 & 16 & 28 & $15: 1$ & $3.05 \mathrm{~ns}$ \\
\hline C9 & 205 & 45 & 0 & 45 & $3: 1$ & $6.53^{*}$ \\
\hline C13 & 887 & 209 & 45 & 254 & $3: 1$ & $4.56^{*}$ \\
\hline $\mathrm{C} 20$ & 908 & 130 & 78 & 208 & $3: 1$ & $24.09 * * *$ \\
\hline $\mathrm{C} 23$ & 404 & 96 & 22 & 118 & $3: 1$ & $1.60 \mathrm{~ns}$ \\
\hline $\mathrm{C} 24$ & 1149 & 15 & 42 & 57 & $15: 1$ & $4.78^{*}$ \\
\hline D1 & 687 & 9 & 28 & 37 & $15: 1$ & $1.60 \mathrm{~ns}$ \\
\hline D3 & 575 & 42 & 1 & 43 & $15: 1$ & $0.53 \mathrm{~ns}$ \\
\hline D4 & 580 & 145 & 14 & 159 & $3: 1$ & $4.78^{*}$ \\
\hline D8 & 1254 & 59 & 13 & 72 & $15: 1$ & $1.52 \mathrm{~ns}$ \\
\hline D9 & 202 & 69 & 7 & 77 & $3: 1$ & $0.81 \mathrm{~ns}$ \\
\hline D10 & 1121 & 62 & 8 & 70 & $15: 1$ & $0.28 \mathrm{~ns}$ \\
\hline Cer6 & 222 & 0 & 0 & 0 & $1: 0$ & - \\
\hline Cer 11 & 212 & 68 & 0 & 68 & $3: 1$ & $0.08 \mathrm{~ns}$ \\
\hline Cer23 & 774 & 226 & 0 & 226 & $3: 1$ & $3.07 \mathrm{~ns}$ \\
\hline Cer 27 & 223 & 41 & 16 & 57 & $3: 1$ & $3.22 \mathrm{~ns}$ \\
\hline Cer34 & 1042 & 20 & 43 & 63 & $15: 1$ & $0.57 \mathrm{~ns}$ \\
\hline
\end{tabular}

*Total white $=$ speckled + albino.

ns: non-significant, $P>0.05 ;{ }^{*} P<0.05 ;{ }^{* *} P<0.01,{ }^{* * *} P<0.001$.

information in $n 2 \times 2$ contingency tables of this sort. The square root of chi-squared is given a sign depending on the direction of the deviation, and the statistic $Z=\Sigma \chi / \sqrt{n}$ calculated. This statistic is distributed as a standard normal distribution. Using this method with these data a value of $Z=11.13(P<0.001)$ is obtained. Second, the selfed progeny of speckled seedlings which have been grown up to maturity (and on the simple two gene hypothesis should produce only albino and speckled progeny) produce a proportion of seedlings that are scored as green. The progeny of six such plants from one family were scored according to four categories: green, more than 50 per cent green, less than 50 per cent green, or albino. The results are given in Fig. 2. It is clear that all plants produce a proportion of seedlings that are indistinguishable from green. However, this proportion is greater in those plants producing the largest proportion of seedlings in the more than 50 per cent class, suggesting that this may simply be an arte- fact of the inability to distinguish seedlings with a very small proportion of white, and thus that some speckled seedlings have been mis-scored as green in all crosses. There is some suggestion in these data, and in the other crosses (Tables 1 and 2) that there may be genetic variance for the degree of speckling, but, formally, parental genotype is confounded with environmental differences. There is no pattern in the proportion of speckleds that would allow for a simple genetic interpretation of the proportion of this phenotype.

\section{Allelism with the albino polymorphism at Schneider Creek, California}

Plants established from seeds collected from this population were selfed and the seeds scored for albinism. They were also found to produce families which either produced all green seedlings, or segregated in $3: 1$ or 15:1 ratios. Some seedlings also showed the speckled 
Table 2 Results of crosses between plants isolated from the Cerrigydrudion population. The plant M16 was grown up from a speckled seedling. The expected ratio is derived from the two gene hypothesis

\begin{tabular}{|c|c|c|c|c|c|c|}
\hline \multirow[b]{2}{*}{ Cross } & \multicolumn{3}{|c|}{ Number of seedlings } & \multirow{2}{*}{$\begin{array}{l}\text { Total } \\
\text { white }\end{array}$} & \multirow{2}{*}{$\begin{array}{l}\text { Expected } \\
\text { ratio }\end{array}$} & \multirow[b]{2}{*}{$\chi^{2}$} \\
\hline & Green & Albino & Speckled & & & \\
\hline$D 9 \times D 4$ & 362 & 39 & 30 & 69 & $3: 1$ & $18.58 * * *$ \\
\hline Cer11 $\times$ Cer 23 & 258 & 78 & 4 & 82 & $3: 1$ & $0.14 \mathrm{~ns}$ \\
\hline Cer $27 \times$ Cer 11 & 393 & 122 & 0 & 122 & $3: 1$ & $0.47 \mathrm{~ns}$ \\
\hline$D 9 \times C 6$ & 477 & 62 & 90 & 152 & $3: 1$ & $0.23 \mathrm{~ns}$ \\
\hline$B 2 \times C 23$ & 896 & 264 & 14 & 278 & $3: 1$ & $1.09 \mathrm{~ns}$ \\
\hline$B 4 \times A 1$ & 406 & 112 & 2 & 114 & $3: 1$ & $2.63 \mathrm{~ns}$ \\
\hline$A 1 \times B 4$ & 560 & 161 & 0 & 161 & $3: 1$ & $2.74 \mathrm{~ns}$ \\
\hline$A 1 \times B 2$ & 579 & 165 & 0 & 165 & $3: 1$ & $3.16 \mathrm{~ns}$ \\
\hline$B 10 \times C 20$ & 517 & 28 & 41 & 69 & $7: 1$ & $0.28 \mathrm{~ns}$ \\
\hline$D 3 \times C 20$ & 660 & 60 & 13 & 73 & $7: 1$ & $4.33^{*}$ \\
\hline$A 1 \times B 9$ & 266 & 33 & 0 & 33 & $7: 1$ & $0.58 \mathrm{~ns}$ \\
\hline$B 2 \times B 10$ & 623 & 87 & 8 & 95 & $7: 1$ & $0.35 \mathrm{~ns}$ \\
\hline$D 1 \times C 6$ & 120 & 4 & 6 & 10 & $7: 1$ & $2.75 \mathrm{~ns}$ \\
\hline$B 9 \times A 1$ & 259 & 34 & 0 & 34 & $7: 1$ & $0.22 \mathrm{~ns}$ \\
\hline$B 10 \times C 6$ & 280 & 28 & 4 & 32 & $7: 1$ & $1.44 \mathrm{~ns}$ \\
\hline$C 20 \times D 6$ & 172 & 23 & 0 & 23 & $7: 1$ & $0.09 \mathrm{~ns}$ \\
\hline$C 6 \times D 8$ & 552 & 36 & 52 & 88 & $7: 1$ & $0.91 \mathrm{~ns}$ \\
\hline Cer34 × D6 & 668 & 46 & 2 & 48 & $15: 1$ & $0.25 \mathrm{~ns}$ \\
\hline M16 $\times$ Cer6 & 416 & 0 & 0 & 0 & $1: 0$ & - \\
\hline$C 13 \times M 16$ & 432 & 94 & 304 & 415 & $1: 1$ & $1.39 \mathrm{~ns}$ \\
\hline$M 16 \times C 13$ & 270 & 6 & 80 & 86 & $1: 1$ & $95.10^{* * *}$ \\
\hline$M 16 \times A 1$ & 195 & 3 & 157 & 160 & $1: 1$ & $3.45 \mathrm{~ns}$ \\
\hline$A 1 \times M 16$ & 247 & 133 & 71 & 204 & $1: 1$ & $4.10^{*}$ \\
\hline$B 6 \times M 16$ & 346 & 5 & 78 & 83 & $3: 1$ & $7.31^{* *}$ \\
\hline
\end{tabular}

ns: non-significant, $P>0.05 ;{ }^{*} P<0.05 ;{ }^{* *} P<0.01 ;{ }^{* * *} P<0.001$.

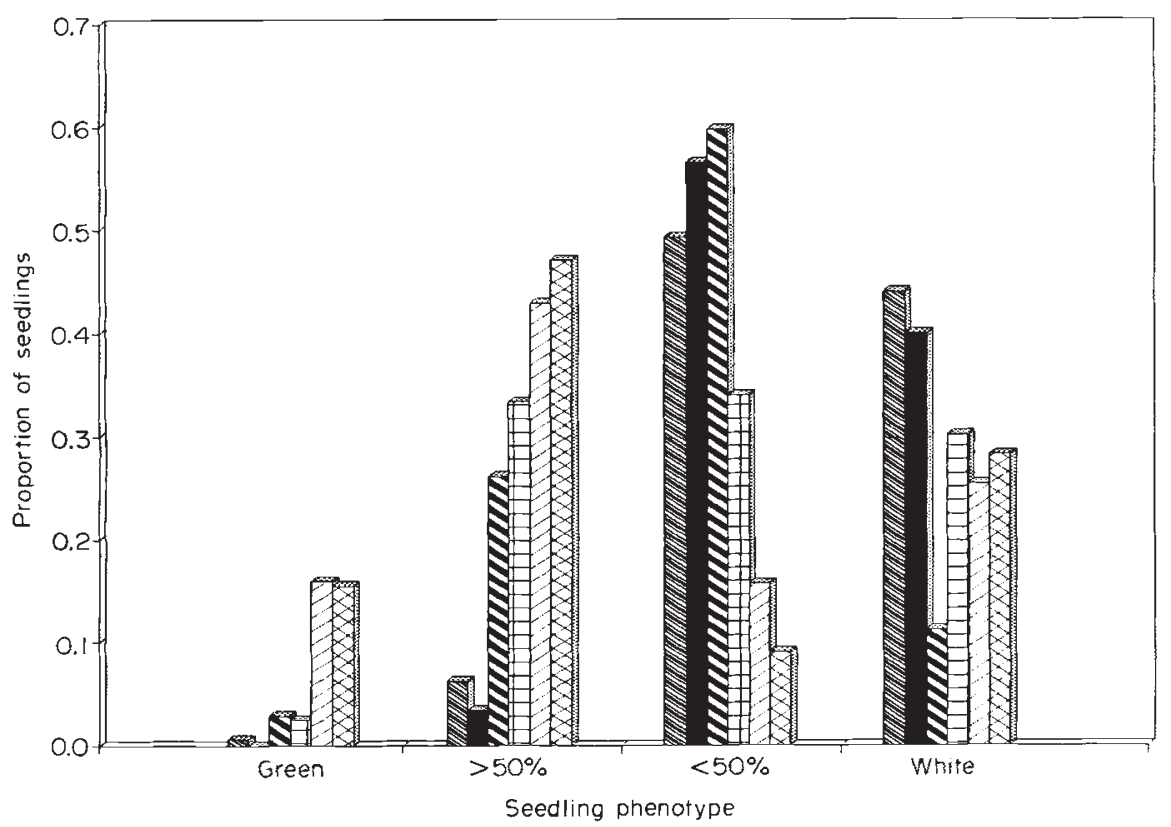

Fig. 2 Selfed progeny of six plants of one family. The plants all had speckled phenotype as seedlings, so should produce only speckled or albino progeny. Their progeny were scored in four categories according to the amount of green that could be seen on the seedlings. 
phenotype. A sample of plants was grown up and both selfed and crossed to a single genotype from Cerrigydrudion, Cer34. This plant was a double heterozygote. The results of these crosses are given in Table 3 . The results are consistent with the genes segregating in the two populations being allelic.

\section{Distribution of the phenotypes at Cerrigydrudion}

The population at Cerrigydrudion has been sampled on a number of occasions since 1976. The method of sampling and scoring allow us to identify three phenotypes: $1: 0$ phenotype (genotypes $A A B B, A a B B, A A B b$, $A A b b$ and $a a B B$ ), $3: 1$ phenotype (genotypes $A a b b$ and $a a B b)$ and $15: 1$ phenotype $(A a B b)$. When sampled by collecting cuttings and selfing them in the greenhouse, the three phenotypes can be unambiguously identified. However, when sampled by collecting the seed produced by individual plants (as in 1976 and 1980), some error is introduced. It is possible to identify 1:0 plants (no albino seeds produced), 3:1 plants (more than $7: 1$ ratio produced), and 15:1 (much less than 7:1 produced) with reasonable certainty, but plants which produce ratios around $7: 1$ cannot be assigned with certainty, except that they must be either $3: 1$ or $15: 1$. The assignment of plants to either 1:0 or $15: 1$ is also theoretically susceptible to error because certain crosses involving a 3:1 maternal parent and various proportions of pollen from 1:0 plants could produce the same ratios. This risk is reduced by taking seed from at least three different capsules.

The proportions found in the different streams (see Fig. 1) of the population are given in Table 4. No sample of stream B or D was possible in 1980 because cattle were kept in the fields, and no flowering stems had survived. The ratios of phenotypes in the different streams is consistent between years (Stream C: $\chi^{2}=0.72$, d.f. $=4$, ns; stream D: $\chi^{2}=0.60$, d.f. $=1$, ns), but there is evidence that there are differences between streams. In particular, stream D (the main river, Afon Ceirw) has a lower proportion of 1:0 plants, and a

Table 4 Frequencies of plants at Cerrigydrudion which produce either $1: 0,3: 1$ or $15: 1$ ratios of albino seedlings on selfing

\begin{tabular}{lrrrrrl}
\hline & & \multicolumn{2}{l}{ Ratio } & & Sampling \\
\cline { 3 - 6 } Population & Date & $1: 0$ & $15: 1$ & $3: 1$ & Seg & method \\
\hline Cerrig & 1976 & 3 & 14 & 12 & 11 & Seed \\
B & 1977 & 0 & 6 & 4 & - & Plant \\
B & 1991 & 6 & 4 & 8 & & Plant \\
Total B & & 6 & 10 & 12 & & \\
C & 1977 & 4 & 3 & 14 & - & Plant \\
C & 1980 & 6 & 5 & 19 & 4 & seed \\
C & 1991 & 11 & 5 & 27 & - & Plant \\
Total C & & 21 & 13 & 60 & 4 & \\
D & 1977 & 0 & 8 & 2 & - & Plant \\
D & 1991 & 0 & 33 & 4 & - & Plant \\
Total D & & 0 & 41 & 6 & & \\
\hline
\end{tabular}

Seg: plants which segregate but which cannot be assigned to either 3:1 or 15:1 classes; Cerrig: in the 1976 sample, records were not kept as to the exact provenance of individual plants within the population; B, C, D: subpopulations (see Fig. 1). (For explanation of sampling methods, see Materials and methods.)

Table 3 Results of selfs of plants isolated from Schneider Creek, and of crosses between the same plants and Cer34. White includes both albino and speckled seedlings

\begin{tabular}{|c|c|c|c|c|c|c|c|c|c|c|}
\hline \multirow[b]{2}{*}{ Plant } & \multicolumn{5}{|c|}{ Selfed progeny } & \multicolumn{5}{|c|}{ Crossed to Cer34 } \\
\hline & Green & White & Ratio & $\chi^{2}$ & $P$ & Green & White & Ratio & $\chi^{2}$ & $P$ \\
\hline $\mathrm{SC1}$ & 124 & 43 & $3: 1$ & 0.05 & ns & 285 & 40 & $7: 1$ & 0.01 & $\mathrm{~ns}$ \\
\hline $\mathrm{SC} 2$ & 774 & 52 & $15: 1$ & 0.03 & ns & 210 & 15 & $15: 1$ & 0.07 & $\mathrm{~ns}$ \\
\hline SC4 & 210 & 10 & $15: 1$ & 1.09 & ns & 434 & 29 & $15: 1$ & 0.00 & $\mathrm{~ns}$ \\
\hline SC9 & 239 & 14 & $15: 1$ & 0.22 & $\mathrm{~ns}$ & 262 & 20 & $15: 1$ & 0.34 & $\mathrm{~ns}$ \\
\hline SC19 & 287 & 37 & $15: 1$ & 14.78 & *** & 390 & 30 & $15: 1$ & 0.57 & ns \\
\hline SC29 & 766 & 172 & $3: 1$ & 22.21 & $* * *$ & 502 & 46 & $7: 1$ & 8.45 & $* *$ \\
\hline SC30 & 136 & 11 & $15: 1$ & 0.38 & ns & 258 & 18 & $15: 1$ & 0.03 & ns \\
\hline SC33 & 246 & 69 & $3: 1$ & 1.61 & ns & 205 & 24 & $7: 1$ & 0.85 & $\mathrm{~ns}$ \\
\hline SC35 & 592 & 38 & $15: 1$ & 0.05 & ns & - & - & - & - & \\
\hline $\begin{array}{r}25 \text { other } \\
\text { plants }\end{array}$ & 6353 & 0 & $1: 0$ & - & & 5864 & 0 & $1: 0$ & - & \\
\hline
\end{tabular}


higher proportion of $15: 1$ plants, than stream $C$ $\left(\chi^{2}=12.73\right.$, d.f. $\left.=2, P<0.01\right)$. Stream $C$ was sampled in both 1980 and 1991 in such a way that the spatial distribution of the phenotypes could be determined. In 1980 samples were taken at approximately $5 \mathrm{~m}$ intervals; in 1991 every plant that was at least $1 \mathrm{~m}$ away from the previous plant was sampled. Table 5 gives the phenotypes identified in each $10 \mathrm{~m}$ stretch of the stream (the main river is at $0 \mathrm{~m}$ ). It is clear that the different phenotypes are interdigitated, so that there is no evidence for single clones extending over very large areas. Although the overall ratio in the stream is stable, there is no evidence for any precise correspondence of phenotype at particular locations between the 11 years, indicating that there has been some turnover of actual plants.

\section{Discussion}

In this paper, I have described a polymorphism for a lethal phenotype determined by two duplicate genes. While polymorphisms for single loci are common, polymorphisms governed by epistatically interacting genes are less frequent. Two of the most studied examples are the case of banding in the snail Cepaea nemoralis (Jones et al., 1977) and cyanogenesis in white clover, Trifolium repens (Hughes, 1991). In the former case there are two unlinked loci, one determining whether the snail is banded, the other deter-

Table 5 Numbers of the three phenotypes identified in each $10 \mathrm{~m}$ stretch of stream C in 1980 or 1991 . In 1991 the culvert under the bridge at $10 \mathrm{~m}$ was blocked and the subsequent flooding had killed all plants for $30 \mathrm{~m}$ upstream of the bridge

\begin{tabular}{|c|c|c|c|c|c|c|}
\hline \multirow{2}{*}{$\begin{array}{l}\text { Stretch } \\
\text { of stream }\end{array}$} & \multicolumn{3}{|c|}{1980 phenotype } & \multicolumn{3}{|c|}{1991 phenotype } \\
\hline & $1: 0$ & $15: 1$ & $3: 1$ & $1: 0$ & $15: 1$ & $3: 1$ \\
\hline $0-10 \mathrm{~m}$ & 0 & 0 & 1 & 0 & 0 & 4 \\
\hline $10-20 \mathrm{~m}$ & 2 & 0 & 1 & - & - & - \\
\hline $20-30 \mathrm{~m}$ & 0 & 1 & 4 & - & - & - \\
\hline $30-40 \mathrm{~m}$ & 0 & 0 & 3 & - & - & - \\
\hline $40-50 \mathrm{~m}$ & 1 & 1 & 0 & 0 & 0 & 1 \\
\hline $50-60 \mathrm{~m}$ & 0 & 2 & 0 & 2 & 1 & 0 \\
\hline $60-70 \mathrm{~m}$ & 1 & 0 & 1 & 0 & 1 & 1 \\
\hline $70-80 \mathrm{~m}$ & 1 & 0 & 0 & 1 & 0 & 4 \\
\hline $80-90 \mathrm{~m}$ & 1 & 0 & 1 & 1 & 0 & 4 \\
\hline $90-100 \mathrm{~m}$ & 0 & 0 & 2 & 0 & 1 & 5 \\
\hline $100-110 \mathrm{~m}$ & 0 & 0 & 1 & 2 & 1 & 3 \\
\hline $110-120 \mathrm{~m}$ & 0 & 0 & 2 & 1 & 1 & 2 \\
\hline $120-130 \mathrm{~m}$ & 1 & 0 & 1 & 3 & 0 & 3 \\
\hline $130-140 \mathrm{~m}$ & 0 & 1 & 2 & 1 & 0 & 1 \\
\hline
\end{tabular}

mining the pattern of banding in banded snails. Cyanogenesis is determined again by two unlinked loci, one determining the presence of a cyanogenic glucoside, the other an enzyme that breaks down the glucoside to produce cyanide. In neither case is it clear what maintains the polymorphism (Jones et al., 1977; Ennos, 1981), but in neither case is one of the genotypes lethal as in the example described here. Numerous cases of lethal polymorphisms are known in cultivated and wild plants (Crumpacker, 1967), and some albino phenotypes are known to be governed by the epistatic interaction of two or more genes (Crumpacker, 1967; Demerec, 1923). There is considerable evidence in other plants that some single locus polymorphisms for chlorophyll-deficient mutants are maintained by single locus heterozygote advantage or pseudo-heterozygote advantage (caused by the mutant being in linkage disequilibrium with another selected locus) (Crumpacker, 1967; Apirion \& Zohary, 1961).

This polymorphism is allelic to one studied by Kiang \& Libby (1972). They showed that plants with the $3: 1$ phenotype from Schneider Creek produced more rhizomes than ones with the 1:0 phenotype (they did not recognize the 15:1 plants). They suggested that this could increase fitness by allowing for more vegetative reproduction. In this species, rhizomes can become detached and, as the plant grows by flowing water, get carried down stream to form new plants. Small parts of plants root giving rise to ramets very readily in this species. In the U.K., this method of propagation must be very important as many wild Mimulus populations consist of sterile hybrids (originally of horticultural origin) between $M$. guttatus and various South American species (Roberts, 1964; McArthur, 1974; Parker, 1975). Many populations apparently consist of single clones (Parker, 1975; M. R. Macnair, unpublished data). Kiang \& Libby (1972) suggested that the greater production of rhizomes, and the perceived heterozygote advantage, were probably due to a linked gene, rather than a direct pleiotropic effect of the locus. With one locus, and a single population, this hypothesis is just tenable, but it requires that the gene is very tightly linked to the favoured locus, and that one of the four gamete types is absent. If linkage is sufficiently tight the production of the fourth gamete by recombination might be delayed but once it has been created the system is unstable and the albino gene will be eliminated. With two loci, and with two independent populations showing the same polymorphism, the linkage hypothesis becomes wildly improbable. As $M$. guttatus is an introduced species to the UK., it could be suggested that these populations may not be independent if the British population was derived originally 
from founders from Northern California. This hypothesis is very unlikely to be correct. This species is morphologically very variable, and the Cerrigydrudion population is very different morphologically to Californian Sierran populations, and does not share other genes with them (Christie \& Macnair, 1987). The albino gene is also not widely distributed in California (M. R. Macnair, unpublished data; Hamrick, 1970, quoted in Kiang \& Libby, 1972). A further hypothesis is that there is no reproduction by seed in these populations, and that all reproduction is vegetative. In such a situation all genes are locked into linkage disequilibrium, and the postulated advantage could be due to any locus. This is also unlikely. Kiang \& Libby (1972) found some seed reproduction in Schneider Creek (they suggest that new plants may have about one-third of the probability of becoming established from seeds as from stolons), and I have observed seedlings at Cerrigydrudion, although I have no idea whether they became established. Certainly the comparison of the distribution of phenotypes between 1980 and 1991 suggests that there is turnover of genotypes over time: it would be surprising if there were no seedling establishment in this turnover. It would not require very much seedling establishment to eliminate genotypes that produce such high proportions of this lethal phenotype.

While it is possible to rule out linkage disequilibrium as a probable cause of this polymorphism, it is much more difficult to do more than speculate on the factors that might be responsible. While the conditions for stable polymorphism in a single locus are well known, there is still no general solution to the two locus problem (Renaud \& Morton, 1991). It is clear that it is neither necessary nor sufficient for the double heterozygote to be the fittest genotype (Karlin, 1975), and that it is not straightforward to maintain a stable internal polymorphism with epistatic interactions, particularly when the genes are unlinked. It will be necessary to do a detailed study of fitnesses of the genotypes in the field to determine whether differences in survivorship or fecundity can explain this polymorphism. One other possibility is raised by the detection by Kiang \& Libby (1972) of a high mutation rate of this system, and by the speckled nature of some seedlings. It could be that this system is controlled by unstable nuclear genes, and that the high mutation rate to albinism, and the speckled phenotype, are caused by the insertion and excision of a transposable genetic element. Other similar cases are known (Kirk \& Tilney-Bassett, 1978). The polymorphism would then be influenced by the rate of mutation induced by transposition. However, the same speckled phenotype can be produced by stable nuclear genes (Kirk \& Tilney-Bassett, 1978), and it is not necessarily easy to maintain a polymorphism by this means when selection is strong (Charlesworth, 1991).

Finally, it is necessary to consider briefly why Kiang \& Libby (1972) failed to recognize that the system they were studying was controlled by two loci. To score the albino seedlings, Kiang grew only 40 seeds per capsule, and did not score speckled seedlings as albinos (Kiang, 1970). With only 40 seeds per capsule, the expected number of albinos is less than three, and so it is not surprising that he failed to notice the $15: 1$ segregations, particularly if he rejected speckled seedlings.

\section{Acknowledgements}

I thank Quinton Cumbes for help with scoring some of the families, and Dr Alastair Robertson for critically reading the paper. Rodney Fry drew the map.

\section{References}

APIRION, D. AND ZOHARY, D. 1961. Chlorophyll lethal in natural populations of the orchard grass (Dactylis glomerata L.). Genetics, 46, 393-399.

CHARLESWORTH, B. 1991. Transposable genetic elements in natural populations with a mixture of selected and neutral insertion sites. Genet. Res. Camb., 57, 127-134.

CHRISTIE, P. AND MACNAIR, M. R. 1987. The distribution of postmating reproductive isolating genes in populations of the yellow monkey flower, Mimulus guttatus. Evolution, 41, 571-578.

CRUMPACKER, D. w. 1967. Genetic loads in Maize (Zea mays L.) and other cross-fertilized plants and animals. Evol. Biol., 1, 306-424.

DEMEREC, M. 1923. Inheritance of white seedlings in maize. Genetics, 8, 561-593.

ENDler, J. A. 1986. Natural Selection in the Wild. Princeton University Press, Princeton.

ENNOS, R. A. 1981. Manifold effects of the cyanogenic loci in white clover. Heredity, 46, 127-132.

EVERITT, B. S. 1977. The Analysis of Contingency Tables. Chapman \& Hall, London.

HUGHES, M. A. 1991. The cyanogenic polymorphism in Trifolium repens L. Heredity, 66, 105-116.

JONES, J. S., LEITH, B. H. AND RAWLINGS, P. 1977. Polymorphism in Cepaea: a problem with too many solutions? Ann. Rev. Ecol. Syst., 8, 109-143.

KARLIN, s. 1975. General two-locus selection models: some objectives, results and interpretations. Theor. Pop. Biol., 7, 364-398.

KIANG, Y. T. 1970. A natural population of Mimulus guttatus maintaining a high frequency of an albino gene. Ph.D. Thesis, University of California, Berkeley.

KIANG, Y. T. AND LIBBY, W. J. 1972. Maintenance of a lethal in a natural population of Mimulus guttatus. Amer. Nat., 106, 351-367. 
KIRK, J. T. O. AND TILNEY-BASSETt, R. A. E. 1978. The Plastids:

Their Chemistry, Structure, Growth and Inheritance, 2nd edn. Elsevier North Holland, Amsterdam.

MCARTHUR, E. D. 1974. The cytotaxonomy of naturalized British Mimulus. Watsonia, 10, 155-158.

PARKER, P. F. 1975. Mimulus in Great Britain - a cytotaxon- omic note. New Phytol., 74, 155-160.

RENAUD, J.-C. AND MORTON, J. R. 1991. A numerical solution to the equilibria of the two-locus two-allele selection model. Biometrics, 47, 1127-1133.

ROBERTS, R. H. 1964. Mimulus hybrids in Britain. Watsonia, 6, $70-75$. 